\title{
Drogadição no cárcere: questões acerca de um projeto de desintoxicação de drogas para pessoas privadas de liberdade
}

\author{
Drug addiction in prison: questions about a project of drug \\ detoxification to incarcerated people
}

\section{Drogadicción en la cárcel: cuestiones acerca de un proyecto de desintoxicación de drogas para personas con su libertad condicionada}

\section{Helena Salgueiro Lermen*}

Pontifícia Universidade Católica do Rio Grande do Sul - PUC-RS, Porto Alegre, Rio Grande do Sul, Brasil

\section{Tamires Dartora**}

Pontifícia Universidade Católica do Rio Grande do Sul - PUC-RS, Porto Alegre, Rio Grande do Sul, Brasil

\section{Carine Capra-Ramos***}

Pontifícia Universidade Católica do Rio Grande do Sul - PUC-RS, Porto Alegre, Rio Grande do Sul, Brasil

\begin{abstract}
Resumo
Neste estudo teórico, tivemos como objetivo analisar um projeto de desintoxicação de drogas, voltado exclusivamente para as pessoas privadas de liberdade no Rio Grande do Sul, calcado na lógica da abstinência total. Apesar de a literatura apontar que a redução de danos (RD) é uma estratégia privilegiada para tratarmos da questão do uso de drogas pela população carcerária, o que encontramos na prática são ações que preconizam a abstinência total, tanto no processo penal, quanto nas prisões. Um exemplo desta lógica é o projeto acima citado, sustentado pelo modelo de proibição do uso e da recaída. Entendemos a complexidade em efetivar ações de RD no cárcere em função das especificidades destes espaços. Porém, as drogas fazem parte do cotidiano prisional e precisam ser percebidas como um problema que vai além da figura do preso: trata-se do nó social, tanto dentro quanto fora do cárcere.
\end{abstract}

Palavras-chave: drogas, sistema prisional, abstinência, redução de danos.

\begin{abstract}
In this theoretical study the aim was to analyze a specific project of drug detoxification exclusively directed to incarcerated people. This referred project is based on the logic of total abstinence. Although literature emphasizes harm reduction as a privileged strategy to deal with drug use in prisons, what we recognize are actions that emphasize abstinence, both in
\end{abstract}


criminal proceedings and in prison units. One example of this type of action is the project mentioned above, sustained by a model that prohibits drug use and relapse. We understand the complexities involved in carrying out actions of harm reduction in prisons, given the specificities of this place. However, the use of drugs is part of prisons' routines. As such, it needs to be approached as a problem that goes beyond any individual prisoner; it is a part of the social node, both outside and inside prisons.

Keywords: drugs, prison system, abstinence, harm reduction.

\begin{abstract}
Resumen
En este estudio teórico tuvimos como objetivo analizar un proyecto de desintoxicación de drogas centrado exclusivamente en personas con su libertad condicionada en Rio Grande do Sul, fundamentado en la lógica de la abstinencia total. Aunque la literatura señala que la reducción de daños (RD) es una estrategia primordial para hacer frente a la cuestión del uso de drogas en la población carcelaria, lo que encontramos en la práctica son las acciones que promueven la abstinencia total, tanto en los procesos penales, como en las cárceles. Un ejemplo de esta lógica es el mencionado proyecto, apoyado en la prohibición del uso y el modelo de recaída. Somos conscientes de la complejidad de llevar a cabo acciones de RD en la cárcel en función de las especificidades de estos espacios. Sin embargo, las drogas son parte de las prisiones de todos los días y tienen que ser percebidas como un problema que vá mas allá de la figura del prisionero: es el nodo social, tanto dentro como fuera de la prisión.
\end{abstract}

Palabras Clave: drogas, régimen penitenciario, abstinencia, reducción de daños.

\title{
1 Introdução
}

O debate acerca dos modelos de atenção à saúde de usuários de álcool e outras drogas tem problematizado as práticas e a resolução dos problemas de saúde da população. A complexidade da questão do uso de drogas e as possíveis intervenções são discutidas por diferentes setores da sociedade civil e do Estado (Canoletti \& Soares, 2005). Esses debates partiram da intenção de formular e implantar políticas públicas que envolvessem a temática da drogadição (Alves, 2009).

Historicamente, as primeiras intervenções do governo brasileiro na área da drogadição datam do início do século XX quando, por meio da criação de um aparato jurídico, foi preconizado o controle do uso e do tráfico de drogas, com a intenção de garantir a segurança do país (Machado \& Miranda, 2007). No que se refere ao consumo de drogas, - Brasil adotou neste período uma abordagem repressiva e proibicionista, influenciada por convenções internacionais. Em 1911, o país afiliou-se à Convenção de Haia, que instituiu o primeiro tratado internacional de controle sobre a venda de ópio, morfina, heroína e cocaína. Além disso, reuniões da Organização das Nações Unidas (ONU) em 1961, 1971 e 1988 - conhecidas como as ConvençõesIrmãs - reforçaram a necessidade de se criar medidas de repressão à 
oferta e ao consumo de toda substância que pudesse levar ao uso abusivo, com a criação da Comissão de Narcóticos. A finalidade da comissão era formular políticas para o controle e a repressão internacional às drogas (Alves, 2009).

A política proibicionista em relação às drogas teve sua origem no início do século XIX nos Estados Unidos, devido à crescente industrialização e o consumo de bebidas alcoólicas e de ópio. As explicações utilizadas por esta política em relação ao consumo de drogas remontam a um modelo moral e ao modelo de doença.

Para o primeiro, o uso de substâncias se configura como uma prática delituosa, em que o usuário passa a ser identificado como criminoso. Portanto, a medida de enfrentamento e as consequências orientadas por essa perspectiva são o encarceramento, a aplicação de medidas de segurança ou transação penal, criminalizando a conduta do usuário. No Brasil, este modelo foi incorporado em 1924, por meio do Decreto 4.294 do Código Penal Brasileiro, que prescrevia a pena de prisão para aqueles que comercializassem drogas ilícitas (Machado \& Miranda, 2007).

Já o modelo de doença entende o consumo e a dependência como um estado patológico. As intervenções sustentadas por este modelo são orientadas ao tratamento e à reabilitação. No Brasil, a partir dos anos de 1970, com a lei 5.726 (Brasil, 1971), a legislação nacional passou a ser influenciada pela medicina, que forneceu subsídios científicos para justificar e legitimar o controle do uso de drogas, apontando a internação em estabelecimentos hospitalares dos "infratores viciados" como uma alternativa de intervenção (Alves, 2009, p. 2314).

Apesar das diferenças entre os modelos, ambos admitem a eliminação total do consumo e a abstinência como exclusiva meta do tratamento (Alves, 2009). A noção de tratamento sustentada por ideologias de abstinência total pressupõe que somente a partir desta o usuário de drogas, entendido como desviante das regras sociais, pode ser aceito socialmente pelo seu ato, em uma espécie de ajustamento e "purificação" (Moraes, 2008, p. 128). É devido a esta conotação moral atribuída ao consumo de drogas que a recaída é revestida por um sentimento de vergonha por aqueles que lutam contra o uso, visto que supostamente fracassaram diante da obrigação de se manterem abstinentes. Assim sendo, a lógica da abstinência é, antes de tudo, imposta pela sociedade em função de seu moralismo, mais do que propriamente sustentada por uma escolha do sujeito.

A estratégia alternativa ao modelo proibicionista para o enfrentamento de questões relacionadas ao consumo de álcool e outras drogas é o modelo da Redução de Danos (RD). As políticas públicas de drogas brasileiras vêm se mostrando permeáveis a este enfoque a partir de 1976, através da lei 6.368 (Brasil, 1976). Esta lei, muito embora reafirme a psiquiatria e a consequente medicalização 
como aliadas dos mecanismos de repressão ao uso de drogas no país, favoreceu a criação de estabelecimentos especializados para o tratamento na rede pública de saúde, ampliando a abordagem sobre o tratamento dos usuários de drogas (Machado \& Miranda, 2007). A lei 6.368 auxiliou a consolidação do Sistema Nacional de Prevenção, Fiscalização e Repressão de Entorpecentes e do Conselho Federal de Entorpecentes (CONFEN), criados e regulamentados em 1980. O CONFEN, atualmente denominado de Conselho Nacional Antidrogas (CONAD), é um órgão normativo responsável por formular políticas públicas relacionadas às drogas. Por algum tempo, o Conselho dedicou-se às ações de repressão ao consumo, à produção e ao tráfico de drogas. No entanto, ainda que o CONFEN tenha iniciado suas práticas visando à proibição e o combate às drogas, algumas iniciativas tiveram grande relevância no cenário brasileiro das políticas publicas, a saber, o apoio aos centros de referência em tratamento, pesquisa e prevenção, às comunidades terapêuticas e aos programas de redução de danos voltados para a prevenção da transmissão de HIV/AIDS (Alves, 2009; Garcia, Leal, \& Abreu, 2008).

A política de RD procura romper com uma construção histórica, social e econômica em torno das abordagens de "combate às drogas" baseadas em concepções moralistas e repressoras (Bucher \& Oliveira, 1994 , p. 137). Dessa forma, a RD é definida como um conjunto de medidas em saúde que preconizam a diminuição das consequências danosas do uso de drogas (Nardi \& Rigoni, 2005), sem necessariamente produzir uma inibição completa do consumo. Isso porque esta prática prega como princípio o respeito à liberdade de escolha, afirmando a responsabilidade do indivíduo perante o seu tratamento e o uso de drogas.

A RD, portanto, centra-se nas necessidades sociais de saúde do usuário, "tendo em vista uma releitura social da questão das drogas e o reconhecimento do uso prejudicial e dependência como um problema de saúde pública" (Alves, 2009, p. 2313). Esta abordagem é construída a partir de dois argumentos: o de que uma sociedade completamente sem drogas é utópica e o de que a guerra às drogas vai contra os princípios éticos e direitos civis das pessoas, ferindo o direito à liberdade do uso (Moraes, 2008).

O enfrentamento da problemática do uso de drogas busca a implantação de políticas setoriais específicas, que visem à melhoria das condições de acesso aos serviços e levem em consideração os aspectos de vulnerabilidade ao consumo de drogas, resultando na reinserção social de usuários. Assim, espera-se na RD que as atividades planejadas para lidar com a questão do uso e abuso das drogas sejam consideradas a partir de uma lógica de redução dos fatores de vulnerabilidade dos usuários (Alves, 2009).

De acordo com Ayres, França-Junior, Calazans e Saletti-Filho (2008) existem três componentes interligados entre si que configuram as 
situações de vulnerabilidade dos sujeitos. O componente individual da vulnerabilidade está associado à qualidade das informações e à capacidade dos sujeitos de elaborá-las e incorporá-las aos seus repertórios cotidianos. Já os componentes sociais da vulnerabilidade dizem respeito à obtenção das informações, às condições de metabolizá-las e ao poder de colocá-las em prática. O acesso às informações não depende apenas do indivíduo, mas também dos meios de comunicação, de educação, dentre outros que devem estar disponíveis ao sujeito. Por fim, o componente programático (ou institucional) faz a ponte entre os componentes individual e social e diz respeito aos programas estatais de prevenção e cuidado. Este componente está vinculado à qualidade das políticas públicas e como elas impactam o grau de vulnerabilidade dos sujeitos.

Logo, as políticas públicas influenciam a situação de vulnerabilidade dos sujeitos, uma vez que esta é, em parte, determinada pela qualidade dos recursos e gerenciamentos propostos pelos programas de prevenção e de cuidado e a facilidade de acesso a eles. 0 programa de RD busca articular estes recursos e ações, a fim de proporcionar intervenções em saúde que levem em consideração as vulnerabilidades nas quais os sujeitos estão expostos.

A Política do Ministério da Saúde para a Atenção Integral a Usuários de Álcool e Outras Drogas (Brasil, 2003a) elenca como uma de suas diretrizes o apoio e o incentivo à RD. Segundo este documento, para promover uma política de saúde coerente, as distintas estratégias (retardo, redução de danos e superação do consumo) devem ser complementares, não concorrentes (Nardi \& Rigoni, 2005). De acordo com Machado e Miranda (2007), foi a partir deste documento que o Ministério da Saúde atestou o seu compromisso e responsabilidade de enfrentar os problemas associados ao consumo de álcool e outras drogas.

Esta política amplia a noção de uso/abuso de drogas como um problema social, questionando o proibicionismo e a lógica de repressão/punição. Neste sentido, propõe a mudança nos modelos assistenciais, garantindo a melhoria das condições de acesso aos serviços de atendimento a cada cidadão (Brasil, 2003a). A Política propôs, então, a implantação de uma rede de assistência integral no Sistema Único de Saúde (SUS), responsabilizando-o pela garantia de acesso à atenção especializada, até então contemplada por instituições privadas e não-governamentais (Alves, 2009).

Assim, as diretrizes da atual política de saúde propuseram a implantação de Centros de Atenção Psicossocial Álcool e Outras Drogas (CAPSad). Situados no contexto da Reforma Psiquiátrica, os Centros de Atenção Psicossocial (CAPS) funcionam como dispositivo que articulam e tecem a rede de saúde mental do SUS (Brasil, 2004). A atuação dos CAPSad visa promover a atenção à saúde de usuários de álcool e outras drogas, inseridos em seu território e comunidade, 
com a finalidade de considerar os mais variados dispositivos na busca da inclusão social dos usuários e seus familiares. Portanto, nesta abordagem são considerados os princípios da cidadania e dos direitos dos usuários, pautados em uma política de redução de danos (Alves, 2009; Moraes, 2008).

Já na segunda década dos anos 2000, com o advento do uso do crack, que passa a ser considerado um problema de saúde pública, o Governo Federal instituiu o Plano Integrado de Enfrentamento ao Crack e Outras Drogas (Brasil, 2010a; Brasil, 2010b). As metas deste plano são a prevenção ao uso e a garantia de tratamento e reinserção social de usuários de crack e outras drogas. Para isto, tem a pretensão de estruturar, integrar, articular e ampliar as ações que contemplem os públicos vulneráveis. O plano visa à contribuição e à implantação de medidas de enfrentamento em três eixos: prevenção, cuidado e combate ao tráfico de drogas.

Assim, os estados passaram a se organizar de modo a atender a esta nova demanda em saúde mental. Desde 2011, o Governo Estadual de São Paulo, por exemplo, instituiu a internação compulsória temporária como medida de política de saúde pública para o tratamento de indivíduos dependentes de crack. O Governo Estadual do Rio de Janeiro começou a intervir da mesma maneira a partir de 2013, quando as autoridades passaram a defender este tipo de medida (Sturm, 2013). O Rio Grande do Sul (RS), por sua vez, não incluiu em suas ações de saúde mental a internação compulsória, por entender que já há uma previsão legal para mesma, não necessitando de uma nova legalização sobre a temática.

Há, portanto, a preocupação das autoridades estatais em fazer com que a população em geral acredite que a única solução para a problemática da dependência química é a internação compulsória (Osellame, 2013). Contudo, a ação de internação compulsória, além de violar os direitos dos indivíduos, discrimina um determinado grupo social. Neste sentido, os indivíduos que estão no espaço público utilizando drogas devem ser "compulsoriamente recolhidos" (Kinoshita, 2013b, p. 22).

Deste modo, o crack é considerado por parte das autoridades estatais como um caso de epidemia, embora esta concepção seja questionada por diversos profissionais de saúde (Kinoshita, 2013a; Loccoman, 2012). Por exemplo, dados elencados por Loccoman (2012) mostram que $12 \%$ da população paulistana é dependente de álcool, mas apenas $0,05 \%$ usam crack, refutando a ideia de epidemia do consumo desta droga.

A gravidade do uso do crack está vinculada a uma série de fatores de risco e vulnerabilidade, tais como: saúde precária, abandono escolar, exploração sexual, desemprego, trabalho infantil, uso de outras drogas, inexistência de projeto de vida, violência familiar, baixa autoestima, falta de acesso a bens econômicos e de consumo (Dalbosco, 
2011). Segundo Melotto (2009), a vulnerabilidade ao uso do crack se apresenta tanto na esfera pessoal (relacionada a fases da vida e a momentos de crise, por exemplo), quanto na esfera social. Sobre esta última, a autora aponta a precariedade das condições de habitação, de trabalho e de saúde, bem como a proximidade do tráfico de drogas como fatores que favorecem o consumo desta substância. Logo, estão mais suscetíveis ao uso de drogas, em especial ao crack, aquelas pessoas que vivenciam processos de exclusão social. Esta, por sua vez, configura um tipo de violência pautada na opressão a determinados grupos, classes, nações ou indivíduos que não têm o mesmo acesso às conquistas da sociedade (Minayo, 1994).

A medida de internação compulsória responde a alguns sentimentos da sociedade, tais como o medo, a insegurança e a impotência. A partir da internação compulsória o usuário de crack é visto como um perigo social, uma vez que perdeu a sua capacidade de autodeterminação em função dos efeitos da droga. Por isso, é demandado ao Estado que contribua com ações de força e de controle à sociedade (Kinoshita, 2013a). A internação, deste modo, é tida como a única medida capaz de resolver o problema e demonstraria que a sociedade não está preparada ou disposta a trabalhar na causa do uso de drogas.

Em contraste com a internação compulsória, pautada na lógica da abstinência total, deve-se levar em consideração o tratamento da dependência química em uma rede substitutiva, em uma perspectiva baseada na noção de um sujeito biopsicossocial e pautada no território familiar e comunitário. De acordo com Kinoshita (2013a), este tipo de ação em saúde questiona a eficácia de ações pontuais, buscando olhar para o problema de uma maneira complexa, integral, em que o planejamento de ações seja sustentado a partir da causa do problema, ou seja, da vulnerabilidade às drogas.

Dentre os grupos mais vulneráveis ao uso de drogas está a população prisional (Guimarães, et al., 2006; Ferreira Filho, Turchi, Laranjeira \& Castelo, 2003). No presente texto buscamos analisar um projeto de desintoxicação de drogas voltado exclusivamente para as pessoas privadas de liberdade no RS, calcado na lógica da abstinência total. Este projeto foi idealizado pelo Ministério Público gaúcho, é financiado pelo Governo do Estado e já atendeu, desde a sua implantação em 2011, a mais de 500 pessoas. Para a melhor compreensão desta ação estatal de saúde mental, a seguir discutimos dados acerca da relação entre o uso de substâncias ativas, a criminalidade e o cárcere. Após, analisamos o projeto de desintoxicação acima citado e questionamos a possibilidade de se efetivarem medidas alternativas à abstinência total, que preconizem ações de RD nas prisões. 


\section{0 uso de drogas, a criminalidade e o cárcere}

O uso, o abuso e a dependência de substâncias psicoativas incidem fortemente sobre a população prisional (Guimarães, Santos, Freitas, \& Araujo, 2008; Torres \& Gomes, 2005; Ferreira Filho et al., 2003). 0 consumo de substâncias ilícitas pode se iniciar antes do encarceramento e estar diretamente ligado à conduta delitiva. Segundo o Plano Nacional de Política Criminal e Penitenciária (Brasil, 2011), a criminalidade no país está fortemente vinculada à dependência química, apontando que os crimes mais comuns (furtos, roubos e tráfico de drogas) são frequentemente cometidos para prover o consumo pessoal de drogas.

Como discutido anteriormente, o consumo de drogas está associado a diversas formas de vulnerabilidade. Paulilo e Jeolás (2000) pontuam que dentre os jovens de baixa renda existem duas razões primordiais para a iniciação ao consumo de substâncias psicoativas. A primeira razão é que para esta população o uso de drogas está associado a sentimentos de proteção, de pertença, de força e de poder dentro de suas comunidades. A segunda razão diz respeito à proximidade das residências destes jovens, comumente situadas em comunidades pobres, com o narcotráfico.

Tal proximidade com o tráfico não apenas facilita o inicio do uso de drogas, como também a inserção da juventude na criminalidade. Paulilo e Jeolás (2000) apontam que o crime possibilita a estes jovens pobres o acesso a bens de consumos tão valorizados em nossa sociedade capitalista. Já para Melotto (2009), muitos usuários se envolvem com a venda de substâncias ilícitas visando à manutenção do uso de drogas. Tal envolvimento expõe os jovens a situações de violência, decorrentes da conduta delitiva e de disputas territoriais próprias do tráfico de drogas.

De acordo com Wacquant (2008), desde o início do século XIX o consumo de drogas passou a ser visto como algo perigoso e vinculado a determinados grupos sociais. Dessa forma, alguns modos de viver passaram a ser criminalizados, resultando em uma imposição de valores econômicos e morais neoliberais e 0 consequente controle de populações socialmente vulneráveis. A realidade retratada pelo autor diz respeito ao contexto norteamericano, mas pode ser facilmente transposta para uma análise do cenário brasileiro.

Ao olharmos os dados sociodemográficos da população prisional, percebemos tanto em âmbito nacional quanto estadual que a maior parte dela é composta por pobres, oriundos de contextos marcados por diversas formas de vulnerabilidade (Monteiro \& Cardoso, 2013). De um total de 548 mil presos no Brasil, 42\% possuem ensino fundamental incompleto, $23 \%$ são condenados por tráfico de drogas, $48 \%$ têm entre 18 e 29 anos e 38\% são de cor parda. Os dados do 
RS corroboram os dados nacionais. O estado possui cerca de 30 mil pessoas presas, sendo a maioria jovem (48\% têm até 29 anos), de baixa escolaridade (59,5\% não completaram o ensino fundamental) e condenadas por tráfico de drogas (33\% estão presos por este delito). A única diferença em relação aos dados nacionais é a questão da cor da população encarcerada, já que $66 \%$ das pessoas presas no RS se autodeclaram brancos (Brasil, 2012). Entretanto, é importante salientar que a população negra total do estado é de 16\% (IBGE, 2010) e que no sistema prisional esta porcentagem sobe para $34 \%$ (Brasil, 2012), indicando um importante dado referente ao marcador raça/cor no contexto prisional.

O que se constata é que o Brasil está criminalizando a pobreza, indicando o componente pragmático da vulnerabilidade (Ayres et al., 2008) de determinados grupos sociais. Neste sentido, o Estado não garante os direitos sociais a certa parcela da população, o que fomenta a conduta delitiva e, consequentemente, o encarceramento desta. Wacquant (2011) observou que o desinvestimento na assistência social nos EUA foi acompanhado de um aumento no número de instituições carcerárias no país. Esses dados sugerem que os mesmos sujeitos que se beneficiariam de programas assistenciais acabam sendo punidos pelo Estado por um sistema econômico e social desigual. Portanto, a negligência do Estado no que se refere à garantia dos direitos sociais básicos resulta na criminalização de uma parcela da população, não por acaso daquela mais desassistida socialmente. Dessa forma, o Estado tem lidado com questões sociais como se fossem questões penais, encarcerando os mais pobres, os marginalizados econômica e socialmente.

Quando analisamos o perfil dos indivíduos encarcerados no Brasil chegamos à óbvia conclusão de que estes, em sua maioria, são oriundos de contextos marcados por profundas vulnerabilidades. Ao chegar ao cárcere, estes sujeitos terão de lidar com novos tipos de problemáticas. Uma delas diz respeito às condições físicas e estruturais das prisões. A capacidade total do sistema prisional nacional encontra-se em 310 mil vagas, entretanto a população carcerária é de 548 mil presos (Brasil, 2012), ou seja, o sistema opera a $76 \%$ acima da capacidade máxima das instituições carcerárias brasileiras. No RS as instituições prisionais estão igualmente superlotadas, funcionando a $36 \%$ acima da sua capacidade (Brasil, 2012). Salienta-se aqui que a superlotação é inconstitucional, pois o Art 5o da Constituição Federal (Brasil, 1988) assegura ao apenado o respeito à integridade física e moral.

Além dos problemas advindos das precárias condições estruturais, há ainda outras consequências resultantes da superlotação das unidades prisionais. Dentre estas, podemos elencar a violência sexual entre os presos, a proliferação de doenças graves e o elevado consumo de drogas. 
Ao se pensar em drogadição no cárcere, uma das primeiras questões que emerge é como, com toda o aparato de segurança existente nas prisões, as substâncias psicoativas ilícitas conseguem estar presentes nestes espaços? Para responder a esta questão é necessário pensarmos na funcionalidade das drogas no sistema prisional. Apesar dos esforços da equipe de segurança nas revistas e no controle dos muros das prisões, as drogas são encontradas no cárcere. Neste contexto, as substâncias psicoativas constituem um dispositivo que ameniza as tensões próprias desta instituição. De acordo com Guimarães et al. (2006, p. 54), "a 'visita íntima', assim como a 'droga' funcionam para acalmar os ânimos e fazer funcionar a prisão". Portanto, o uso de drogas na prisão é compreendido a partir de duas perspectivas distintas e contraditórias: se por um lado ele é condenado e controlado, por outro parece haver um certo acordo tácito sobre os seus benefícios neste contexto.

Já para as pessoas presas, conjecturamos que o uso de drogas seja adotado como estratégia para lidar com as condições características do cárcere, tais como a insalubridade das prisões, a exposição frequente à violência, a falta de perspectivas dos sujeitos encarcerados quanto ao futuro, o isolamento e o processo de despersonalização. Não há dados oficiais que esclareçam o número de pessoas usuárias de substâncias psicoativas na prisão, tampouco as motivações destas pessoas para o consumo de drogas. O fato de que o uso de substâncias no cárcere seja ilegal dificulta a que se chegue a um número preciso de usuários, pois as pessoas presas não admitem o uso de drogas nestes espaços (Carvalho, Valente, Assis \& Vasconcelos, 2006).

Em uma pesquisa realizada no Rio de Janeiro, com uma amostra de 2.039 participantes, a maior parte dos entrevistados (74\%) relata ter usado álcool antes de serem presos, seguido por maconha $(61 \%)$ e cocaína (52\%), enquanto $33 \%$ deles afirmaram continuar o uso de drogas na prisão (Carvalho et al., 2006). Segundo pesquisa realizada em Porto Alegre com pacientes psiquiátricos que já tiveram passagem por instituições prisionais, a porcentagem de uso drogas no cárcere chega a 40\% (Guimarães et al., 2008). Em Nota Técnica, a Secretaria Estadual de Saúde do RS (Rio Grande do Sul, 2012a) aponta para $80 \%$ de dependentes químicos no cárcere gaúcho.

Embora não possamos precisar o número de usuários de substâncias psicoativas no sistema prisional, isto não diminui a gravidade do problema. No caso do RS, a Secretaria da Segurança Pública, através da Superintendência dos Serviços Penitenciários (SUSEPE), anunciou em 2012 a construção de uma prisão exclusiva para dependentes químicos (Rio Grande do Sul, 2012b). O local será batizado como Centro de Referência para Privados de Liberdade Usuários de Álcool e Outras Drogas e contará com 351 vagas. Tal iniciativa vem sendo questionada por outras esferas do Governo Estadual, sobretudo pela 
Secretaria de Saúde, por entender que a iniciativa fere os princípios da Lei Federal 10.216 (Brasil, 2001) e da Lei Estadual 9.716 (Rio Grande do Sul, 1992), que dispõem sobre a Reforma Psiquiátrica. Segundo os princípios da Reforma, o lugar de internação em saúde mental deve ser os hospitais gerais e não as prisões ou instituições totais. Entende-se que a criação desse espaço geraria uma dupla estigmatização do sujeito, sendo ele reconhecido como usuário de drogas e privado de liberdade.

A medida da criação de uma prisão exclusiva para usuários de drogas expõe as dificuldades do Estado em administrar a questão da dependência química no sistema prisional. Faz-se necessário, portanto, pensarmos em políticas de drogas que considerem as especificidades do sistema penal. No RS, algumas alternativas vêm sendo pensadas. Além da criação desta prisão exclusiva para dependentes químicos, desde 2011 está em prática um projeto de desintoxicação para indivíduos no sistema prisional, que discutiremos a seguir.

\section{Projeto de dependência química para pessoas privadas de liberdade no RS}

Desde março de 2011 o RS realiza um projeto pioneiro de atenção às pessoas privadas de liberdade dependentes de substâncias psicoativas. Trata-se de um convênio entre a Secretaria Estadual de Saúde (SES/RS) e o Hospital Vila Nova (HVN) de Porto Alegre. Segundo o convênio pactuado, 18 (dezoito) leitos da ala específica para atendimento a pessoas presas são ofertados para desintoxicação de drogas. Os objetivos do projeto são proporcionar às pessoas em situação de prisão uma alternativa de combate às drogas, diminuir a recaída e uso de drogas, bem como fortalecer/reestabelecer os vínculos entre os apenados e seus familiares.

Para participar do projeto a pessoa presa precisa manifestar interesse (não existe internação compulsória nesta ação). Após, o sujeito encarcerado passa pela avaliação de um psicólogo e de um assistente social que trabalham na prisão. Se os profissionais concordarem que o caso é adequado à internação, o nome da pessoa é encaminhado para o setor de inteligência da SUSEPE, que avaliará se o indivíduo está envolvida com alguma facção criminosa e se existe o risco de resgate do sujeito no trajeto até o HVN. Caso o parecer do setor de inteligência seja favorável, a pessoa entra em uma lista de espera para a internação.

Durante todo o processo de internação a pessoa conta com a rede de atenção à saúde do município. Os participantes do projeto permanecem por 21 dias internados no HVN, onde recebem atendimento individual e grupal de profissionais da psicologia, serviço 
social, medicina, terapia ocupacional e enfermagem, em uma abordagem multiprofissional. Durante este período, eles ficam abstinentes de qualquer tipo de droga, lícita ou não.

O projeto também prevê que as pessoas sigam em acompanhamento em saúde nas prisões, através do trabalho das equipes de saúde prisional que atuam dentro das unidades penais ou da rede municipal de saúde depois do período de internação. Estas equipes surgiram a partir do Plano Nacional de Saúde no Sistema Penitenciário, Portaria Interministerial 1777 (Brasil, 2003b), são compostas por, no mínimo, sete profissionais de saúde (psicólogo, assistente social, médico, enfermeiro, técnico de enfermagem, odontólogo e auxiliar de consultório dentário) e têm como objetivo efetivar o direito constitucional de atenção integral à saúde aos indivíduos no sistema prisional. Em janeiro de 2014, foi instituída a Política Nacional de Atenção Integral à Saúde das Pessoas Privadas de Liberdade no Sistema Prisional (PNAISP) que reformula a composição mínima das equipes de saúde no sistema prisional (ESP). Nesta nova composição, é possível incluir nas ESP profissionais para atuar especificamente com saúde mental (Brasil, 2014). O RS aderiu à PNAISP em maio de 2014 e está em processo de implantação deste modelo de atenção à saúde nas prisões do Estado. Quando implantadas, serão estas equipes que darão continuidade ao acompanhamento dos participantes do projeto.

A ideia do projeto é que após o período de internação as pessoas retornem à casa penal de origem e sejam encaminhadas a uma galeria destinada à reabilitação. Apesar de o projeto ser destinado a todas as pessoas privadas de liberdade do RS, apenas uma instituição prisional possui tal espaço: o Presídio Central de Porto Alegre (PCPA). Esta foi uma exigência do Ministério Público (MP) do RS, por entender que as pessoas não teriam condições de se manter abstinentes em galerias onde outros fizessem o uso de drogas.

Desde o início do Projeto, em março de 2011, mais de 500 pessoas presas foram internadas no HVN, quase todas de prisões de Porto Alegre. O maior número de internados é oriundo do PCPA, em função da existência da galeria específica para pessoas que passaram pelo processo de desintoxicação. Atualmente, cerca de 60 homens seguem em tratamento dentro desta instituição penal, recebendo atendimento diferenciado das duas equipes de saúde prisional que atuam nesta instituição.

Participar do projeto de desintoxicação resulta em benefícios a seus participantes. O primeiro deles é ser alojado - quando da volta dos 21 dias de desintoxicação - em um espaço em que não há superlotação, situação incomum no PCPA (são cerca de 4460 presos para uma capacidade de 2069). O segundo benefício é receber um atendimento diferenciado dos profissionais da atuam no cárcere, pois além das ações frequentes de duas equipes de saúde prisional que 
atuam no PCPA, os presos que participaram do projeto recebem o atendimento de uma psicóloga e de uma assistente social que trabalham exclusivamente para os cerca de 60 homens presos na galeria livre de drogas. Esta atenção representa um privilégio, considerando que, segundo dados de dezembro de 2012, o RS possuía em média um psicólogo para cada 218 presos (Brasil, 2012). Há ainda um terceiro benefício, relacionado ao momento da avaliação criminológica. Quando o apenado cumpre tempo suficiente de sua pena para progredir de regime, o juiz solicita que este seja avaliado por um psicólogo e/ou um assistente social. O juiz se baseia, dentre outras fontes, nestas avaliações para determinar se o benefício de abrandamento de pena será concedido ao sujeito preso. Conjecturamos que o fato de ter ou estar participando do Projeto de Desintoxicação é considerado importante, tanto pelos técnicos que realizam as avaliações, quanto pelo juiz. Por fim, supomos que existam outros benefícios, mais simbólicos, como ser visto dentro do cárcere (pelos profissionais que atuam no PCPA) e fora dele (pelo juiz e pela sociedade) como um "bom preso". Em outras palavras, o participante do projeto é percebido socialmente como alguém em quem se deposita a esperança de ressocialização, ao passo que os demais, que não manifestam interesse de passar pelo projeto, são desmerecidos e desacreditados.

O Projeto de Desintoxicação está calcado na lógica da abstinência total. Tanto durante a internação, quanto do retorno ao PCPA, não são permitidas recaídas no uso de drogas. Quando estão na galeria específica do projeto, as pessoas presas fazem exames de urina com frequência, para comprovar que não consumiram substâncias psicoativas. Caso os exames atestem o uso de qualquer tipo de droga, a pessoa é expulsa da galeria. Há, portanto, um forte controle externo (através dos exames de urina) e interno (através da vigilância dos demais presos), que provavelmente motiva a abstinência dos sujeitos durante o período em que estiverem na galeria especial. A recaída, quando ocorre, é vista como um desvio individual que deve ser punido, reforçando a lógica da abstinência. Nesta lógica, as causas da recaída não são consideradas, como propõe Nascimento (2006), pois o foco da ação punitiva é o indivíduo que fracassou em sua obrigação de se manter abstinente. No caso do cárcere, conjecturamos que as causas da recaída são diversas, tais como a distância dos antigos companheiros de galeria, os sentimentos de isolamento, de desesperança e de falta de apoio, a ausência de outros mecanismos para lidar com os desafios e dificuldades da prisão e as representações pessoais associadas às drogas.

É importante salientar que os sujeitos que têm o interesse de realizar a desintoxicação hospitalar, mas que não querem ir para galeria sem drogas, não são aceitos no Projeto. No entanto, a obrigatoriedade de 
mudar de galeria é bastante questionável. Nascimento (2006), em relação à internação compulsória, aponta que não há impacto no comportamento do sujeito apenas o retirando do contexto onde se faz o uso das drogas. Para o autor, esta conduta reforça uma ineficiência do Estado em colocar em prática políticas que partam de uma lógica de RD, responsabilizando exclusivamente o indivíduo pelo uso de drogas.

O Projeto, portanto, não aceita outras formas de conduta frente à drogadição que não a abstinência total. No entanto, ao tratarmos de uma medida de tratamento à dependência de drogas sustentadas por esta lógica nos questionamos se as suas ações não representariam um retrocesso em relação às políticas públicas voltadas à drogadição. Ao retomarmos o histórico de tais políticas no Brasil, vemos que há um reconhecimento gradual de que as drogas são um problema social e de que a RD é ação indicada para a maior parte dos casos de dependência química. Por que, então, ações baseadas nesta lógica são tão raras no cárcere?

Entendemos que as prisões, por serem espaços de controle e vigilância do Estado, são ambientes pouco propícios para efetivação de ações de RD. Na literatura, são escassos os estudos que tratam deste tipo de prática no sistema prisional. Em um deles, são pontuadas as possibilidades de aplicação de medidas de redução de danos no campo do Direito, substituindo o processo penal convencional por tratamento monitorado do infrator dependente químico (Weigert, 2010). De acordo com a autora, no RS, o projeto Justiça Terapêutica tem como objetivo evitar a prisionização dos sujeitos, encaminhando-os para grupos terapêuticos de autoajuda. Entretanto, os três grupos aos quais os usuários são encaminhados Narcóticos Anônimos, Alcoólicos Anônimos e Amor Exigente - têm suas práticas norteadas pela lógica da abstinência total. Embora o Judiciário entenda o não encarceramento como uma medida de redução de danos, as medidas alternativas ofertadas proíbem o uso de substâncias psicoativas, sendo, portanto, baseadas na obrigatoriedade do comportamento abstinente do usuário.

Em outro estudo, Bravo (2009) selecionou e avaliou 12 projetos que têm o apoio do Ministério da Saúde e que visam à implantação da prática de redução de danos em instituições prisionais de nove estados do Brasil. Através de entrevistas com vários atores do sistema prisional, o autor constatou a dificuldade de se colocar em prática ações que preconizem a distribuição de seringas e agulhas, uma vez que esta conduta ainda é considerada fora dos padrões da legalidade pelas autoridades.

No entanto, as dificuldades acima elencadas - especialmente a distribuição de insumos para o consumo de drogas - contrariam as diretrizes do Plano Nacional de Saúde no Sistema Penitenciário do Ministério da Saúde (Brasil, 2003b). Este plano definiu como 
prioridade o tratamento de DST/AIDS para pessoas em situação de privação de liberdade, visto que se trata de uma população vulnerável à infecção e transmissão de doenças sexualmente transmissíveis. Contudo, Bravo (2009) observou que em algumas prisões, a distribuição de folhetos com informações necessárias para um melhor cuidado no uso de drogas por vias injetáveis era permitida. Compreendemos assim, que ações que atenderiam especificamente os objetivos da RD, tais como a distribuição de seringas, não são efetivadas, ao passo que aquelas que não estão diretamente vinculadas ao consumo de drogas, a saber, distribuição de folhetos e outros materiais informativos, são bem aceitas nos espaços prisionais.

Em relação aos indivíduos presos que foram entrevistados, o autor acima notou que havia discrepâncias nos discursos daqueles que foram capacitados como multiplicadores de saúde, ou seja, que promovem ações de redução de danos. Os multiplicadores afirmaram que a distribuição de folhetos informativos é fundamental para o sucesso das ações de RD no cárcere, porém divergiam quanto à distribuição de insumos para consumo de drogas, como seringas, por exemplo. Muitos acreditavam que esta distribuição poderia incentivar o uso de substâncias psicoativas. Chama-nos a atenção que os próprios detentos capacitados para intervir por meio da RD têm receio quanto à distribuição de insumos para uso de drogas.

Bravo (2009) descreve que as resistências à RD no cárcere não são exclusividade dos sujeitos presos e também estão presentes nos discursos dos médicos participantes do estudo. Estes profissionais, segundo o autor, não apenas demonstraram dificuldades em aceitar medidas de RD no cárcere, como também questionavam o direito de acesso à saúde das pessoas presas. Este questionamento demonstra a forma como os indivíduos privados de liberdade encontram obstáculos para a efetivação de seus direitos constitucionais básicos em função, primordialmente, do julgamento moral da sociedade, que de uma maneira geral não reconhece os indivíduos presos como um sujeito de direitos.

Assim, os poucos exemplos de medidas de RD enfrentam resistência de diversos atores envolvidos, inclusive dos próprios sujeitos encarcerados. Bravo (2009) aponta como dificultador das ações de RD no cárcere a ideologia de punição e do castigo, especialmente pela RD se configurar em uma abordagem que afirma o respeito à liberdade de escolha e à responsabilidade do indivíduo perante o seu tratamento.

Entendemos que mesmo as instituições prisionais que se propõem a realizar ações de RD não as executam conforme as diretrizes do Ministério da Saúde (Brasil, 2003a), ou seja, através da distribuição de insumos - seringas, agulhas e cachimbos - para consumo de drogas. A crença amplamente disseminada, de que o sujeito preso 
não deve ter seus direitos constitucionais garantidos é, ainda, um entrave à efetivação destas ações. A pouca ou nenhuma oferta de medidas de RD no cárcere nos remete ao moralismo, às contradições e às inconsistências que perpassam as ações em saúde nas prisões e a um modelo que ainda entende a drogadição como um desvio pessoal e não como um problema social.

\section{Considerações finais}

Ao longo dos anos, são tensionadas as discussões acerca da legislação brasileira referente ao consumo de drogas no Brasil, para que as drogas deixem de ser apresentadas como uma ameaça à sociedade e passem a ser reconhecidas como um problema social e de saúde pública. A literatura aponta que existem grupos socialmente mais vulneráveis ao consumo de drogas, confirmando a drogadição, como um problema social, necessitando de ações que preconizem a cessação, diminuição ou prevenção dos fatores que originam este problema (Paulilo \& Jeolás, 2000; Melotto, 2009; Dalbosco, 2011).

A RD é uma estratégia de ação frente à drogadição que reconhece os fatores de vulnerabilidade aos quais os indivíduos estão expostos e compreende o sujeito usuário de drogas como alguém que sofre múltiplas influências do seu entorno. Neste sentido, o uso de drogas se constitui como uma prática que só pode ser significada dentro do contexto mais amplo de existência dos indivíduos.

Portanto, a RD surge como estratégia privilegiada ao tratarmos da questão do uso de drogas pela população carcerária, especialmente ao enfatizarmos as múltiplas vulnerabilidades às quais estes sujeitos estão expostos. Entretanto, o que encontramos na prática são ações que preconizam a abstinência total, tanto no processo penal, quanto nas instituições prisionais. Um exemplo desta lógica é o Projeto de Dependência Química para Pessoas Privadas de Liberdade no RS, sustentado pelo modelo de proibição do uso e da recaída.

Embora não sejamos contrárias ao referido projeto, entendendo os benefícios que ele possa representar aos usuários de drogas privados de liberdade, nossa crítica centra-se na rigidez a partir da qual ele opera. Tal rigidez é expressa pela proibição e punição a eventuais recaídas, avaliadas a partir de mecanismos externos e internos de controle do preso em reabilitação.

Entendemos a complexidade em efetivar ações de RD no cárcere conforme preconiza o Ministério da Saúde (Brasil, 2003a), em função das especificidades destes espaços. Porém, as drogas fazem parte do cotidiano das prisões e precisam ser percebidas como um problema que vai além da figura do preso: trata-se do nó social, tanto dentro quanto fora do cárcere. Assim sendo, reforçamos a ideia de Paulilo e Jeolás (2000, p. 58) de que "somente quando a questão das drogas 
for compreendida como parte de uma política de saúde que tenha por objetivos tanto a prevenção como a redução de danos, o enfoque passará do produto, isto é, a droga, para a pessoa que a utiliza, ou seja, o cidadão".

\section{Referências}

Alves, V. S. (2009). Modelos de atenção à saúde de usuários de álcool e outras drogas: Discursos políticos, saberes e práticas. Cadernos de Saúde Pública, 25(11), 2309-2319.

Ayres J. R. C. M., França-Júnior I., Calazans G.J., \& Saletti-Filho H.C. (2008). O conceito de vulnerabilidade e as práticas de saúde: novas perspectivas e desafios. In: D. Czeresnia \& C. M. Freitas (Orgs.). Promoção da saúde: conceitos, reflexões, tendências. Rio de Janeiro: Fiocruz.

Bravo, O. A. (2009). Avaliação de ações de redução de danos no sistema penitenciário brasileiro. Psicología para América Latina: Revista Eletrónica Internacional de La Unión Latinoamericana de Entidades de Psicología, 18. Recuperado em 05 de janeiro, 2014, de http://psicolatina.org/18/reducion.html

Brasil. (1971). Lei $\mathrm{N}^{0} 5.726$, de 29 de outubro de 1971. Dispõe sobre medidas preventivas e repressivas ao tráfico e uso de substâncias entorpecentes ou que determinem dependência física ou psíquica e dá outras providências. Brasília: Ministério da Justiça.

Brasil. (1976). Lei № 6.368, de 21 e outubro de 1976. Dispõe sobre medidas de prevenção e repressão ao tráfico ilícito e uso indevido de substâncias entorpecentes ou que determinem dependência física ou psíquica, e dá outras providências. Brasília: Ministério da Justiça.

Brasil. (1988). Constituição da República Federativa do Brasil. Brasília: Ministério da Justiça.

Brasil. (2001). Lei Federal 10.216 de 6 de abril de 2001. Proteção e direitos das pessoas portadoras de transtornos mentais e redireciona o modelo assistencial em saúde mental. Brasília: Ministério da Saúde.

Brasil. (2003a). A Política do Ministério da Saúde para a Atenção Integral a Usuários de Álcool e Outras Drogas. Brasília: Ministério da Saúde.

Brasil. (2003b). Portaria Interministerial MS/MJ $\mathrm{n}^{\circ}$ 1777. Plano Nacional de Saúde no Sistema Penitenciário. Brasília: Ministério da Saúde e Ministério da Justiça.

Brasil. (2004). Saúde Mental no SUS: Os Centros de Atenção Psicossocial. Brasília: Ministério da Saúde. 
Brasil. (2010a). Crack, é possível vencer. Brasília: Ministério da Saúde.

Brasil. (2010b). Decreto $n^{\circ}$ 7.179, de 20 de maio de 2010. Plano de Enfrentamento ao Crack e outras drogas. Brasília: Ministério da Saúde.

Brasil. (2011). Plano Nacional de Política Criminal e Penitenciária. Brasília: Ministério da Justiça.

Brasil. (2012). Sistema Integrado de Informações Penitenciárias Infopen. Brasília: Ministério da Justiça.

Brasil. (2014). Política Nacional de Atenção Integral à Saúde das Pessoas Privadas de Liberdade no Sistema Prisional. Brasília: Ministério da Saúde e Ministério da Justiça.

Bucher, R. \& Oliveira, S. (1994). O discurso do "combate às drogas" e suas ideologias. Revista de Saúde Pública, 28(2), 137-145.

Canoletti, B. \& Soares, C. B. (2005). Programas de prevenção ao consumo de drogas no Brasil: uma análise da produção científica de 1991 a 2001. Interface - Comunicacão, Saúde, Educação, 9(16), 115-29.

Carvalho, M. L., Valente, J. G., Assis, S.G., \& Vasconcelos, A.G.G. (2006). Perfil dos internos no sistema prisional do Rio de Janeiro: especificidades de gênero no processo de exclusão. Ciência \& Saúde Coletiva, 11(2), 461-471.

Dalbosco, C. (2011). Política Nacional sobre Drogas e o Plano Integrado de Enfrentamento ao Crack e Outras Drogas. Trabalho apresentado em Oficina a Assistência Social no Plano Nacional de Enfrentamento ao Crack e outras Drogas: um debate necessário.

Ferreira Filho, O. F., Turchi, M. D., Laranjeira, R., \& Castelo, A. (2003). Perfil sociodemográfico e de padrões de uso entre dependentes de cocaína hospitalizados. Revista de Saúde Pública, 37 (6), 751-759.

Garcia, M. L. T, Leal, F.X. \& Abreu, C. C. (2008). A política antidrogas brasileira: velhos dilemas. Psicologia \& Sociedade; 20 (2), 257266.

Guimarães, C. F., Meneghel, S. N., Zwetsch, B. E.; Silva, L.B., Grano, M.S., Siqueira, T. P. \& Oliveira, C. S. (2006). Homens apenados e mulheres presas: estudos sobre mulheres de presos. Psicologia \& Sociedade, 18(3), 48-54.

Guimarães, C. F., Santos, D. V. V., Freitas, R. C. \& Araujo, R. B. (2008). Perfil do usuário de crack e fatores relacionados à criminalidade em unidade de internação para desintoxicação no Hospital Psiquiátrico São Pedro de Porto Alegre (RS). Revista de Psiquiatria, 30(2), 101-108.

IBGE (2010). Censo 2010. Recuperado em 12 de dezembro, 2013, de http://www. ibge.gov. br/home/estatistica/populacao/censo2010 /default.shtm. 
Kinoshita, R. T. (2013a). Política atual de álcool e outras drogas e perspectivas. In: Conselho Federal de Psicologia (Org.). Drogas, Direitos Humanos e Laço Social (53-60). Brasília: CFP.

Kinoshita, R. T. (2013b). Em nome da proteção do cuidado, que formas de sofrimento e exclusão temos produzido? In: Conselho Federal de Psicologia (org.), Drogas, Direitos Humanos e Laço Social (21-24). Brasília: CFP.

Loccoman, L. (2012). A polêmica da internação compulsória. Mente Cérebro Web Site. Recuperado em 13 de Outubro, 2013, de http://www2.uol.com.br/vivermente/artigos/a_polemica_da_int ernacao_compulsoria.html.

Machado, A. R. \& Miranda, P. S. C. (2007). Fragmentos da história da atenção à saúde para usuários de álcool e outras drogas no Brasil: da Justiça à Saúde Pública. História, Ciências, Saúde, 14(3), 801-821.

Melotto, P. (2009). Trajetórias e usos de crack: estudo antropológico sobre trajetórias de usuários de crack no contexto de bairros populares de São Leopoldo. Dissertação de Mestrado, Instituto de Filosofia e Ciências Humanas, Universidade Federal do Rio Grande do Sul.

Minayo, M. C. S. (1994). A Violência Social sob a Perspectiva da Saúde Pública. Caderno de Saúde Pública, 10, 07-18.

Monteiro, F. M. \& Cardoso, G. R. (2013). A seletividade do sistema prisional brasileiro e o perfil da população carcerária. Civitas, 13(1), 93-117.

Moraes, M. (2008). O modelo de atenção integral à saúde para tratamento de problemas decorrentes do uso de álcool e outras drogas: percepções de usuários, acompanhantes e profissionais. Ciência \& Saúde Coletiva, 13(1), 121-133.

Nardi, H. C. \& Rigoni, R. Q. (2005). Marginalidade ou cidadania? A rede discursiva que configura o trabalho dos redutores de danos. Psicologia em Estudo, 10(2), 273-282.

Nascimento, A. B. (2006). Uma visão crítica das políticas de descriminalização e de patologização do usuário de drogas. Psicologia em Estudo, 11(1), 185-190.

Osellame, L. (2013). Parlamentares, especialistas e movimentos sociais debateram a internação compulsória. Assembleia Legislativa do Rio Grande do Sul. Recuperado em 13 de Outubro, 2013, de http://www2.al.rs.gov.br/noticias/ExibeNoticia/tabid/5374/Defa ult. aspx? I dMateria $=283153$.

Paulilo, M. A. S. \& Jeolás, L. S. (2000). Jovens, drogas, risco e vulnerabilidade: Aproximações teóricas. Serviço Social em Revista, 3(1), 39-60. 
Rio Grande do Sul (1992). Lei Estadual no 9.716, de 07 de agosto de 1992. Reforma psiquiátrica no Rio Grande do Sul. Porto Alegre: Secretaria da Saúde e do Meio Ambiente.

Rio Grande do Sul. Secretaria Estadual da Saúde (2012a). Nota técnica referente ao anúncio de projeto de construção de presídio para tratamento de dependentes químicos realizado pela Secretaria de Segurança Pública. Audiência Pública da Procuradoria da República no Rio Grande do Sul sobre a construção de presídios para dependentes químicos.

Rio Grande do Sul. Superintendência dos Serviços Penitenciários (2012b). Susepe cria projeto inédito de presídio para dependentes químicos. Porto Alegre: Superintendência dos Serviços Penitenciários. Recuperado em 13 de Setembro de 2012,

http://www.susepe.rs.gov.br/conteudo.php?cod_menu=4\&cod_ conteudo $=964$.

Sturm, H. A. (2013). Ação no Rio mobilizou mais de 300 profissionais. Estadão Web Site. Recuperado em 12 de Novembro, 2013, de http://www.estadao.com. br/noticias/geral, acao-no-riomobilizou-mais-de-300-profissionais, 998975, 0.htm.

Torres, A. C. \& Gomes M. C. (2005). Drogas e Prisões: Relações Próximas. Revista Toxicodependências, 11(2), 23-40.

Wacquant, L. (2008). O lugar da prisão na nova administração da pobreza. Novos Estudos - CEBRAP, 80, 9-19.

Wacquant, L. (2011). The Wedding of Workfare and Prisonfare Revisited. Recuperado em 05 de Janeiro, 2014, de http://revistaepos.org/arquivos/05/entrevista_Wacquant_ingles .pdf.

Weigert, M. A. B. (2010). Uso de drogas e Sistema Penal: entre o proibicionismo e a redução de danos. Rio de Janeiro: Lumen Juris.

\section{Endereço para correspondência \\ Helena Salgueiro Lermen}

Pontifícia Universidade Católica do Rio Grande do Sul - PUC-RS

Programa de Pós-Graduação em Psicologia

Avenida I piranga, 6681 Prédio 11 sala 937, Bairro Partenon, CEP 90619-900 - Porto

Alegre, RS - Brasil.

Endereço eletrônico: hslermen@gmail.com

\section{Tamires Dartora}

Pontifícia Universidade Católica do Rio Grande do Sul - PUC-RS

Faculdade de Psicologia

Avenida Ipiranga, 6681 Prédio 11, 8o andar, Bairro Partenon, CEP 90619-900 -

Porto Alegre, RS - Brasil.

Endereço eletrônico: tamires_dartora@hotmail.com

\section{Carine Capra-Ramos}

Pontifícia Universidade Católica do Rio Grande do Sul - PUC-RS

Faculdade de Psicologia 
Helena Salgueiro Lermen, Tamires Dartora, Carine Capra-Ramos Drogadição no cárcere: questões acerca de um projeto de desintoxicação de drogas para pessoas privadas de liberdade

Avenida Ipiranga, 6681 Prédio 11, 8o andar, Bairro Partenon, CEP 90619-900 Porto Alegre, RS - Brasil.

Endereço eletrônico: carcapramos@gmail.com

Recebido em: 20/03/2014

Aceito para publicação em: 23/07/2014

\section{Notas}

* Mestranda de Psicologia Social pela Pontifícia Universidade Católica do Rio Grande do Sul.

** Graduanda de Psicologia pela Pontifícia Universidade Católica do Rio Grande do Sul.

*** Graduanda de Psicologia pela Pontifícia Universidade Católica do Rio Grande do Sul. 